\title{
UMA ANÁLISE DA TEORIA DO SUJEITO MORAL A PARTIR DA FILOSOFIa DO DiREITo, DE HEGEL
}

\author{
[ AN ANALYSIS OF THE THEORY OF THE MORAL SUBJECT FROM THE PHILOSOPHY OF RIGHT OF \\ HEGEL ]
}

\begin{abstract}
Resumo: Nesse artigo pretende-se fazer uma breve análise expositiva da compreensão do que seja a teoria do sujeito moral a partir da Filosofia do Direito de Hegel. Para tanto, o texto visa, primeiramente, fazer uma rápida reconstrução dos principais momentos de mediação lógica do conceito de vontade, para situar, do ponto de vista da estrutura da Filosofia do Direito, em que consiste a especificidade da teoria do sujeito moral no âmbito da "Moralidade". Trata-se, ainda, de reconstituir quais são seus momentos internos, e em que sentido esses representam um novo patamar do desdobramento lógico de mediação do conceito de vontade no âmbito subjetivo, bem como, ao mesmo tempo, de apontar a insuficiência desses momentos e mostrar a necessidade de suplantar, de forma logicodialética, a esfera subjetiva da "Moralidade" na esfera objetiva da "Eticidade".
\end{abstract}

Palanras-chaVe: Hegel, Vontade, Direito, Sujeito, Moralidade
ABSTRACT: This article intends to make a brief expositive analysis of the understanding of the theory of the moral subject from Hegel's Philosophy of Right. In order to do so, the text aims, first of all, to make a rapid reconstruction of the main moments of logical mediation of the concept of will, in order to situate, from the point of view of the structure of the Philosophy of Right, the specificity of the theory of the moral subject in scope of "Morality". It is also a question of reconstituting these internal moments, and in what sense they represent a new level of the logical unfolding of the concept of will in the subjective scope, as well as, to point out their insufficiency and show the need to supplant, in a logical-dialectical form, the subjective sphere of "Morality" in the objective sphere of "Ethical".

KEYwORDS: Hegel; Will; Right; Subject; Morality

\section{INTRODUÇÃo}

$\mathrm{N}$ o primeiro parágrafo da Filosofia do Direito está enunciada a tese central e fundamental do direito em sentido amplo, a qual Hegel expressa, sinteticamente, da seguinte forma: "A ciência filosófica do direito tem por objeto a ideia do direito, o conceito do direito e sua efetivação" (FD§1). Toda a arquitetônica dessa obra consiste em apresentar o desenvolvimento lógico-dialético ou especulativo

* Pós-Doutorado em Filosofia pela Pontifícia Universidade Católica do Rio Grande do SulPUCRS. Doutor em Filosofia pela Universidade Estadual de Campinas, UNICAMP. Professor Associado A da Graduação e da Pós-Graduação (Stricto Sensu) em Filosofia da Universidade Estadual do Oeste do Paraná, UNIOESTE.m@ilto: t6ciotta@yahoo.com.br 
do conceito de direito nas suas diferentes figuras de mediação, sendo, cada uma delas em particular, um momento e um modo específico do ser aí do direito enquanto ideia da liberdade.

Cada figura de medição configura um determinado grau de desenvolvimento do conceito do direito ou da efetividade da ideia do direito. Se o "direito tem, por objeto, a ideia do direito", e sendo que a verdade é o resultado, mas também, ao mesmo tempo, o processo do devir do próprio conceito do direito, então a ideia, é a verdade objetiva, a efetiva do direito, quer dizer, a unidade intrínseca e mais elevada entre o conceito e sua exteriorização, entre o ser e o dever ser, entre o conceito do direito e sua efetividade.

Em suma, esse é o estado de questão cujos desdobramentos, investigaremos a seguir.

\section{O SENTIDO MORAL DO DIREITO}

Pode-se perceber que, para Hegel, o direito, em sentido amplo, ultrapassa a dimensão do direito abstrato, entendido como direito positivo, formal, contratual. $\mathrm{O}$ direito remete a uma realidade mais profunda em sua compreensão, e, portanto, mais extensa em sua abrangência, envolvendo além do direito abstrato, que é o direito positivo moderno, a moralidade, enquanto autoconsciência da vontade subjetiva. Tratase, como diz Hegel, de circunscrever o seu "saber e o seu querer". Além disso, envolve também a "Eticidade", enquanto forma institucional, social e objetiva de efetivação, desse saber e desse querer, regrado pelos princípios formais do direito positivo. Princípios esses mediados social e institucionalmente pela livre associação dos interesses corporativos, na sociedade civil, e controlados em seus possíveis desvios, pela administração da justiça.

Com a administração da justiça visa-se preservar e restaurar o direito, na pessoa daquele em que este foi lesado, e garantir, ao mesmo tempo, ao transgressor daquele direito um julgamento justo, portanto, imparcial levado a efeito por uma terceira pessoa, o juiz. A figura do juiz, representante do poder público, funciona como uma espécie de termo médio entre as duas vontades particulares - a que sofreu o dano e a que provocou o dano -, e a vontade universal.

A administração da justiça visa suprimir e superar o jogo deletério entre as vontades particulares e reinseri-las, dialética e hierarquicamente, numa realidade ainda mais profunda e abrangente. Trata-se da vontade universal, representada pelo Estado, não apenas como uma realidade institucional exterior à vontade subjetiva, capaz de manter sob seu domínio toda a realidade conflituosa provinda do movimento do particular. Ao contrário, a vontade universal, coloca-se como a Aufhebung da contradição entre a forma e o conteúdo, entre o subjetivo e o objetivo, entre o interior e o exterior, e entre o finito e o infinito.

Nesse sentido, a "vontade é universal, porque nela toda a delimitação e todo detalhe singular particular são suprassumidos, enquanto eles residem somente na diversidade do conceito e de seu objeto ou de seu conteúdo" (FD\$24). Tal vontade congrega em si a força unificadora do conceito catalisando a diversidade do conteúdo da vontade particular (subjetiva) sem, com isso, lhe suprimir sua autonomia. A vontade universal é, antes, em termos lógico-ontológicos, o pleno desenvolvimento e a possibilidade da existência objetiva do conteúdo da subjetividade, e, ao mesmo tempo, o fim, tanto do direito positivo, como do direito da vontade subjetiva. 
Entendido desse modo, o direito torna-se o processo gradual de determinação da ideia do direito, abarcando a série das determinações da vontade livre. Ora, tal vontade, - aqui, deve ser compreendida como um princípio do direito, da moralidade e da eticidade que perfaz o caminho da pura abstração formal até atingir a identidade concreta entre a forma e o conteúdo, ou seja, a sua determinação singular. O que Hegel nos mostra é que o caminho do desenvolvimento lógico desse processo de determinação inicia-se, na Filosofia do Direito, com o conceito de pessoa jurídica, que na ordem das determinações da "vontade livre em si e para si", é a categoria lógica imediata, universal e abstrata. Portanto, completamente formal e vazia de conteúdo. Assim, o conceito de pessoa jurídica, apresenta-se como fundamento e pedra angular sobre a qual se apoia todo o edifício da Filosofia do Direito.

\section{O CONCEITO DE PESSOA JURÍdICA}

Para evidenciar com maior clareza a delimitação e o uso que Hegel faz do conceito de pessoa, no interior da lógica de determinação da vontade livre, no Espirito Objetivo, torna-se útil, de maneira didática, mostrar comparativamente a peculiar compreensão e extensão que Kant confere a este conceito. Consideramos útil, mesmo que meramente de cunho ilustrativo, fazer uma breve analogia entre os dois autores em questão porque, de certo modo, a filosofia kantiana permeia e transpassa a filosofia de Hegel como uma espécie de resíduo conceitual, apesar das críticas que, este, ela dirija.

O conceito de pessoa, em Kant, concentra um duplo aspecto, qual seja, jurídico e moral. Neste sentido, tal conceito tem uma extensão maior do que aquela que Hegel atribui a essa mesma noção no início da FD, mais precisamente, nos $\S 34$ a 39. Para Kant, ser pessoa, significa ser portador de uma capacidade moral, própria de um ser livre e racional, ou seja, que só se submete às leis que ele deriva da própria razão, e que as concebe como universalmente válidas, seja para si mesmo, seja para todos os demais. Somente um ser racional, livre e autônomo pode ser pessoa. Nisso reside o fato de que suas ações possam lhe ser imputadas, dado que, ao eleger a lei, à qual escolheu livremente se submeter à luz de um imperativo da própria razão, independentemente de qualquer forma de coerção externa, ele pode ser responsabilizado pelas consequências de sua ação. Isso tudo, pelo menos no âmbito do direito, apesar que, do ponto de vista moral, não se leve em conta as consequências da ação, mas o motivo pelo qual se cumpre determinada lei moral. Embora se possa distinguir entre a lei moral, que obriga internamente, e a lei jurídica, que obriga externamente, o fundamento de ambas espécies de lei será sempre obra de uma razão livre e autônoma.

Em Hegel, porém, o conceito de pessoa, tem um sentido estritamente jurídico vindo a representar o ponto de partida de mediação do conceito de "vontade livre em si e para si". Neste particular, o conceito de pessoa, não só se diferencia do emprego que Kant faz dele, mas assume um novo sentido sistemático na ordem das determinações logico-dialéticas do conceito de vontade livre na Filosofia do Direito.

O conceito de pessoa jurídica ou pessoa do direito, em Hegel, designa a capacidade jurídica, ou seja, o poder em responsabilizar-se pelas consequências jurídicas dos próprios atos enquanto reconhecidos como mediações da vontade. $\mathrm{O}$ conceito de pessoa jurídica possui um caráter universal e abstrato. É universal porque inclui a todos aqueles que possuem esta capacidade, e é abstrato porque não tem nenhuma determinação de conteúdo. Quer dizer: a única determinidade que o conceito 
de pessoa possui é ser uma universalidade que se refere tanto aos diferentes sujeitos com total indiferença quanto às determinações de conteúdo que cada um possa se dar. É imediata (FD§34) porque não tem nenhuma determinação de conteúdo e porque indica, ao mesmo tempo, o ponto de partida de todo o sistema jurídico colocando-se como fundamento e princípio que dá início ao movimento de autodeterminação da vontade particular. Universalidade e imediatez são duas notas distintas, mas inseparáveis do conceito de pessoa ${ }^{1}$.

A universalidade indica, do ponto de vista formal, que a vontade é livre para si mesma, todavia, enquanto singularidade, ela está desprovida de todo e qualquer conteúdo. Nisso, ela é pura negatividade, ou seja, o eu se sabe na sua finitude como sendo "o infinito, o universal e o livre" (FD§35), consciente de si, pura relação consigo mesmo: o sujeito é pessoa. A pessoa é, na verdade, em termos conceituais, a singularização do espírito que sabe que é livre, mas que ainda carece de uma mediação objetiva, isto é, que "ainda não tem nele mesmo sua particularização e implementação" (EN, §488) numa realidade externa. Trata-se de uma realidade que carece de vontade própria, portanto, que não é fim em si mesma, e por isso mesmo, recebe da vontade livre seu fim. Ao pôr-se como vontade numa realidade externa (particularidade), a pessoa se determina na sua singularidade.

A pessoa é o indivíduo que sabe que é livre, quer dizer, que tem consciência de sua liberdade e, que sabe que todos os demais são igualmente livres. O que se revela, aqui, portanto, é um saber abstrato que ainda não têm a experiência objetiva da liberdade porque a vontade ainda não se exteriorizou na coisa, ou seja, não completou a ponte (mediação) entre o saber interior, subjetivo, e o mundo objetivo fora dela. Deste saber da liberdade decorre que este eu particular que sabe de sua liberdade e igualmente de todo o eu em sentido lógico, implica, como conclusão, o juízo jurídico: "sê uma pessoa e respeita os demais enquanto pessoa" (FD\$36).

Do ponto de vista formal, pode-se deduzir que Hegel, neste particular, inspira-se em Kant ao formular o juízo "este singular é universal", constitutivo do conceito de pessoa. Trata-se de um juízo que implica em sua estrutura lógica uma espécie de imperativo categórico, na medida em que pressupõe a necessidade da universalização de uma máxima de ação. Ora, isso pressupõe, ao mesmo tempo, o reconhecimento do homem com um fim em si mesmo. Com isso, afirma-se que a pessoa jurídica não é um conceito derivado do sistema jurídico, mas, ao contrário, é o próprio princípio e fundamento do sistema (cf. FD§36). Tal conceito é o ponto de partida que alicerça o desenvolvimento e desdobramento de todas as suas figuras até alcançar o seu ápice na teoria do Estado.

O caráter universal da pessoa jurídica implica, necessariamente, o reconhecimento recíproco de todos os demais como pessoas do direito. Em outras palavras, isto consiste em afirmar que este indivíduo particular tem uma dimensão universal que é compartilhada por todos os demais indivíduos, ou seja, que todos são reconhecidos como sujeitos de direitos e obrigações recíprocas, legisladores e súditos.

O dado primordial que, por um lado, individualiza a "vontade livre em si e para si" - o fato de ser reconhecido como pessoa - é, por outro lado, o mesmo dado que faz emergir, em cada particular, a dimensão intersubjetiva, como condição necessária na mediação da vontade particular. Nisso reside a sua universalidade. Hegel, porém, situa outra nota característica do conceito de pessoa - a sua imediatez - que, do ponto de vista formal, indica o ponto de partida do movimento lógico de determinação da vontade livre. 
A imediatez, por outro lado, indica o princípio potencial da vontade em seus momentos logico-conceituais - universalidade, particularidade e singularidade - mas que permanece, ainda, na forma abstrata ou negativa em relação ao mundo exterior. Isso porque a vontade livre ainda não perfez o caminho das mediações inscritas em sua lógica interna que lhe conferem concretude e objetividade (efetividade). Ser livre, aqui, é ser "pessoa" que, enquanto capacidade jurídica, consiste no direito de dispor de coisas e, ao dispor delas, coloca-se numa relação jurídica com outras "pessoas" como seres igualmente livres.

A pessoa diferencia-se de si ao pôr a sua vontade numa coisa exterior e ao relacionar-se com outros indivíduos livres enquanto "pessoas", na medida em que, ambos são proprietários. Portanto, a coisa exterior entendida como propriedade, aparece como elo de mediação entre "pessoas" jurídicas ou entre seres igualmente livres. Já a relação entre vontades, no âmbito do "Direito Abstrato", restringe-se ao direito privado e, neste sentido, limita-se à vontade comum. Ora, nem sempre a vontade particular respeita o contrato por ela mesmo estabelecido, com outra vontade particular. Isso implica o rompimento do acordo firmado entre duas ou mais vontades livres. $\mathrm{O}$ rompimento do contrato abre um conflito entre as vontades particulares, na medida em que, pode causar dano às outras vontades em diferentes proporções e em distintos graus de gravidade.

\section{A JUSTIÇA PUNITIVA E A SUPERAÇÃO DO CONFLITO ENTRE VONTADES PARTICULARES}

Na primeira parte da Filosofia do Direito - "Direito Abstrato" - em sua terceira seção, Hegel, com o conceito do injusto e a sua superação através do conceito de justiça punitiva/retributiva, passa a demonstrar a necessidade e, ao mesmo tempo, a insuficiência do direto positivo moderno no que diz respeito à efetividade da liberdade.

A insuficiência do direto positivo reside no fato deste se restringir às mediações exteriores da vontade particular. Neste particular, estas, não só têm que ser sabidas e observadas, mas internalizadas como o meu próprio querer subjetivo. Por isso, a contradição entre a positividade da lei, que obriga externamente, e a vontade interior subjetiva, é dialeticamente superada com o conceito de sujeito moral. Ora, é a partir desse conceito fundamentalmente que interior e exterior não são mais concebidos, apenas, como dois lados opostos, antagônicos e excludentes. Eles guardam a diferença entre ambos os aspectos a elevando a um grau superior de mediação, no qual encontram um ponto de identidade entre objetividade e subjetividade sem eliminar ou sobrepor nenhuma das duas esferas.

O instituto jurídico desta relação/mediação entre vontades livres, na condição de proprietárias, se dá através do contrato, cuja efetividade é alcançada na esfera da sociedade civil, que, na figura da "Eticidade", situa-se entre a Família e o Estado. No entanto, embora o contrato seja a mediação de uma relação, entre vontades livres (enquanto proprietárias) juridicamente fundada, ele não é suficiente tomado em si mesmo para garantir o cumprimento do acordo estabelecido. Dada a insuficiência do contrato para conter a vontade dentro dos limites previamente estabelecidos abre-se, assim, a partir do próprio contrato, a possibilidade para o atuar contingente e arbitrário da vontade segundo suas próprias prerrogativas.

Sendo assim, as vontades particulares podem romper o contrato. Ora, isto 
significa afirmar que, a priori, elas podem, reciprocamente de forma unilateral, se prejudicarem. A lesão pode se dar em diferentes níveis e, portanto, ferir a vontade em graus diferentes no que diz respeita à gravidade do dano causado à outra pessoa. No final do "Direito Abstrato", Hegel mostra que este processo de mediação da vontade que vai da simples injustiça ao crime, representa um novo passo no desenvolvimento do conceito de vontade. É assim que começa a emergir, aí, uma nova figura (Gestalt) da vontade que consiste na distinção (Untercheidung) entre a vontade universal em si, o conceito de vontade - ou direito em si - e a vontade como singular ou para si, da qual emergiu o delito/crime com a sua transgressão.

Instaura-se, aqui, uma relação de conflito entre a vontade universal e a vontade singular e para sair deste impasse é preciso compreender como se deu esta distinção tanto no crime quanto na vingança (ou justiça vingativa).

É possível mostrar que no delito/crime há uma distinção entre a vontade universal e a vontade singular na medida em que esta última é uma vontade racional porque do contrário, o delito, não seria um ato humano e, portanto, não poderia ser concebido como um crime. Apesar, porém, de haver racionalidade formal presente na ação da pessoa, o delito contradiz, em si mesmo, o direito (legalidade), ou seja, a coexistência entre pessoas livres. É o que bem observa Coll (2001, p. 161): "No delito, a vontade caiu numa contradição: as determinações da vontade entraram em contradição ao colocar em relação de oposição sua universalidade e sua particularidade".

Por isso, no delito, a vontade particular, ao atuar, nega a vontade universal, na medida em que esta é a condição de sua própria realização, posto que, enquanto vontade particular deve realizar o conceito de vontade livre, e, portanto, deve conter a vontade universal. O delito é, definitivamente, uma negação da vontade universal, do direito em si, da liberdade. Ora, em graus distintos, também a justiça vingativa ou a vingança, " $[\ldots]$ introduz a mesma distinção na vontade ainda que em princípio seja resposta ao delito, posto que reage a uma violência anterior e, portanto, <segundo o seu conteúdo é justa> (FD 102). Fato é que, nem por isso, tal justiça é a superação do delito, senão sua perpetuação porque é a resposta particular da vontade subjetiva [...] que só casualmente coincide com a justiça (FD \& 102) (COLL, 2001, p. 161).

A vingança, do mesmo modo que o delito, expõe a distinção entre a vontade universal e a vontade particular. Ora, esta reação é também afirmação da vontade particular contra a universal. Por isso, tanto o delito quanto a vingança terminam na cisão entre a vontade particular e a vontade universal.

A questão é que, para superar o impasse, faz-se necessário dar um novo passo, ou seja, constituir uma nova figura do desenvolvimento da vontade. Esta nova figura consistirá em reestabelecer a unidade entre a vontade universal e a vontade particular na medida em que converte a justiça vingativa em justiça punitiva, quer dizer, o ato de reestabelecer a justiça pela mediação do Estado, a fim de superar a primeira negação pela negação da negação (Estado) desconstruindo o círculo vicioso que se instaurou entre as distintas vontades particulares.

Há que se fazer uma distinção entre o deleito e a justiça vingativa. No delito, não há somente a negação da vontade particular, mas ao negar a vontade particular está, ao mesmo tempo, negando a vontade universal. Com isso, nega-se o próprio conceito de vontade livre em si e para si, enquanto que, na justiça vingativa, não há propriamente a negação da vontade universal, mas apenas a negação da vontade particular no intuito de superar a injustiça sofrida. 
O delito representa a negação absoluta da vontade, ou seja, nega em seu próprio ato o conceito de vontade livre que é a condição de sua própria liberdade. O delito torna impossível a convivência humana ou a coexistência de vontades livres porque elimina o fundamento e a possibilidade de sua existência. Mas tampouco a justiça vingativa consegue superar este impasse, embora não negue a vontade universal enquanto fundamento e possibilidade de sua existência. A sua limitação consiste em permanecer num jogo de ação-reação-contra-reação, entre vontades particulares, o que significa perpetuar o conflito indefinidamente.

Tanto o delito quanto a justiça vingativa são incapazes de superar o impasse embora por razões distintas, conforme mencionado anteriormente. Ao contrário, a justiça punitiva (pena), assegurada e implementada pelo Estado (negação da negação), torna possível superar o impasse travado entre as distintas vontades particulares porque a vontade universal volta unir-se à vontade particular. Isso tudo na medida em que no ato de punir, o Estado visa unicamente o direito, ou seja, reconciliar a vontade particular com o conceito de vontade. Em função disso, a vontade devém para si, tornase efetiva porque foi além da pura universalidade em si - contra a qual atuou o delito agora ela quer a vontade universal como sua (cf. FD 105).

$\mathrm{O}$ que Hegel sugere é que a vontade se torna efetiva porque neste movimento de retorno a si, pela negação da negação, arranca-a da abstração e da fixação na particularidade, conferindo-lhe existência efetiva na vontade singular (cf. FD 106). Ora, pois, com a vontade particular que quer a vontade universal desencadeia-se um duplo movimento. Primeiro, a vontade particular tem, como própria, a vontade universal. Segundo, a vontade universal se torna para si efetiva, ou seja, existe de forma concreta numa vontade particular. Isto porque, justamente na pena, a vontade particular reconciliou-se com o direito, com o próprio conceito de vontade. Esta reconciliação introduz um sentido moral porque traduz o direito em si em direito efetivo por uma deliberação da vontade. Esta superação da oposição entre a vontade universal em si e singular para si é propriamente o que constitui a nova figura da moralidade (cf. FD 103).

A realização da vontade segundo o conceito deve percorrer três passos: primeiro, superar o ser em si (Ansichsein) e a forma de sua imediatez (o Direito Abstrato = propriedade e contrato); segundo, diferenciar-se na oposição entre vontade universal em si e vontade singular para si (delito e vingança). Este movimento de cisão é necessário para que a vontade universal em si adquira realidade na vontade singular para si (necessidade dos extremos). Assim, em terceiro, trata-se de superar a oposição (negação da negação) e, desse modo, como volta a observar Coll (2001, p. 163), “devir vontade para si e efetiva, vontade existente (Dasein) não só como vontade livre em si, senão para si mesma, como negatividade que se refere a si mesma. Este é o passo dado com a justiça punitiva, que abre o caminho para a Moralidade".

\section{O SUJEITO MORAL}

Nos parágrafos (103 e 104 da FD), Hegel expõe a passagem do "Direito Abstrato" 'a "Moralidade". Aqui, o sujeito moral começa a emergir de uma vontade particular que quer o universal como tal. Esta vontade, para Hegel, é equivalente ao conceito de moralidade. Desse modo, pode-se afirmar que o conceito de moralidade deriva da figura do delito, da vingança e da justiça punitiva, ou seja, "da diferenciação 
das determinações da vontade - que no delito e na vingança manifesta-se como opostos - e de sua reconciliação na justiça punitiva" (COLL, 2001, p. 164). Sob esse ângulo, a "Moralidade é compreendida como o verdadeiro reestabelecimento do direito, como sua condição de possibilidade, porque reconcilia a vontade particular e a vontade universal" (COLL, 2001, p. 164).

A mera vingança não representa a superação do delito porque é a resposta de um particular a outro particular. Esta oposição instaura, antes, uma espécie de estado de natureza que se prolonga pelo jogo das oposições entre o delito e a vingança. Porém, tampouco a imposição de um universal exterior que domine os particulares é a saída desta contradição. Somente a reconciliação entre universal e particular pode superar as contradições entre delito e vingança. Deste modo, não há, em Hegel, a tradicional passagem do estado de natureza ao Estado, proposta pelos contratualistas modernos. A passagem do estado de natureza - delito e vingança - para o Estado, em Hegel, se dá através da "Moralidade". Pois bem: isso implica o reconhecimento de normas morais. Tais normas constituem a base para a manutenção do Estado moderno. É delas que emana a força que gera coesão social e, neste sentido, são a própria condição de interação e integração dos indivíduos na esfera social, na qual, realizam a mediação objetiva da vontade subjetiva através das relações intersubjetivas reconhecidas institucionalmente pelo Estado e regradas pela lei positiva.

$\mathrm{Na}$ "Moralidade" a universalidade converte-se em objeto próprio da vontade subjetiva, particular, de modo a estabelecer uma relação (Verhältnis) entre vontade universal e vontade particular. A "subjetividade infinita da liberdade é alcançada quando a personalidade se tem a si mesma como objeto (FD§104), isto é, quando o sujeito particular tem como objeto próprio de sua vontade a universalidade que lhe é própria como pessoa" (COLL, 2001, p. 166). O caráter de ser pessoa define-se essencialmente por ter a universalidade como objeto de sua vontade particular.

O conceito de pessoa é o pressuposto, a partir do qual, se desenvolve todo o sistema do direito. O "Direito Abstrato" apresenta-se como um conjunto de princípios e normas de mediação da vontade universal e abstrata. Sua força normativa e sua eficácia não dependem da vontade subjetiva individual, mas da racionalidade interna, própria ao sistema do direito, no qual todos são reconhecidos como pessoa do direito. Por isso, a "Moralidade" frente ao "Direito Abstrato" não é um novo começo oposto ao sistema do direito, mas o desenvolvimento do mesmo princípio, onde, a vontade subjetiva se coloca como uma espécie de autoafirmação destes princípios e normas. Isso porque ao serem internalizados, funcionam como um elemento de continuidade/passagem/ponte entre a exterioridade objetiva da lei e interioridade da vontade, superando o possível conflito entre a vontade universal, representada pelo sistema do direito, e a vontade subjetiva particular.

O subjetivo é um novo aspecto do desenvolvimento objetivo do sistema do direito e não uma nova premissa. Sob esse prisma, o direito se transforma em norma moral. A moral, por sua vez, preenche um novo requisito no desdobramento do sistema do direito com a emergência de uma nova figura, o sujeito moral; trata-se de uma espécie de ponto de transição entre o conceito de pessoa e o conceito de cidadão. Ora, a vontade livre, infinita em si mesma, sob o ponto de vista moral, já é uma mediação da exterioridade objetiva do direito e não um ponto de partida imediato, fundado puramente na subjetividade, o que a colocaria numa oposição de pura exterioridade em relação ao direito. Ao contrário, a vontade sob o ponto de vista moral, é uma mediação do próprio conceito de direito apresentando-se como um novo momento da ideia da 
liberdade que tem, agora, na subjetividade da vontade, sua existência efetiva. Somente no delito é que a vontade subjetiva para si, se coloca numa oposição de pura exterioridade em relação à vontade universal, ou seja, ao sistema do direito. Mas como o conceito do direito é o desenvolvimento racional da ideia da liberdade, ele vale por si mesmo. Isso explica porque a aplicação da pena por parte do direito visa superar a relação de exterioridade na qual a vontade particular havia se fixado, mostrando que essa só pode ser livre na medida em que quer, igualmente, a vontade universal.

Ao se reconciliar com o próprio direito em si, ela torna racional o interesse da vontade subjetiva particular frente ao sistema do direito. "A autodeterminação da vontade é, ao mesmo tempo, um momento de seu conceito e a subjetividade não é apenas o aspecto do seu ser-aí, porém sua determinação própria (§104). A vontade livre para si, determinada como subjetiva, inicialmente enquanto conceito, ela mesma tem ser-aí, a fim de ser enquanto ideia. Por isso o ponto de vista moral é, em sua figura, $o$ direito da vontade subjetiva" (FD §107).

$\mathrm{O}$ ponto de vista da moralidade apresenta-se, pois, como o momento da reflexão em si da vontade. A personalidade encerra o momento universal da vontade que se define como auto referência do eu pensante, ou seja, sabe e quer o que sabe e, por isso mesmo, sente-se responsável pela ação e pelas consequências contidas nesse saber e querer. Nesse movimento de determinação da vontade está implícito o valor da liberdade subjetiva, na medida em que aí está salvaguardado o direito que cada indivíduo tem de se determinar no curso de sua própria vida e nela encontrar satisfação nas suas escolhas. Este é o momento da autorrealização do sujeito no âmbito da moralidade, mas que exige, em contrapartida, que este respeite noutro, o mesmo direito à autodeterminação. Decorre daí que cada um é responsável pelos seus atos e pelas consequências de suas ações, mas é necessário que estas estejam presentes no seu saber e querer para serem passíveis de responsabilidade moral. Nessa direção, a busca do próprio bem-estar implica igualmente o respeite ao outro, do ponto de vista externo, como pessoa do direito, e como sujeito moral, exige respeito ao direito de cada um determinar sua liberdade individual a partir de um ato interior de sua vontade.

É a vontade particular que quer, ao mesmo tempo, tornar-se vontade universal. Aqui colocam-se em relação, logicamente, dois aspectos distintos da vontade, o particular e o universal, numa mesma e idêntica vontade. Por esta "reflexão em si" a vontade não se relaciona com objetos, mas consigo mesma e assim se converte em sujeito moral. "Assim, a liberdade, que até agora se relacionava no trato com coisas (propriedade) ou com outros através de coisas (contrato) [...] agora devém liberdade subjetiva, em que o sujeito se determina a querer o racional em si conforme o direito" (COOL, 2001, p. 168). O outro não é um limite externo, ou um impedimento para a minha liberdade, mas expressa a condição intersubjetiva para a realização da minha liberdade.

Esta passagem da exterioridade para a interioridade é, na verdade, uma passagem para a autorrrelação interior da vontade, na qual a vontade em si torna-se para si, ou seja, a pessoa do direito passa a ser sujeito moral. Na "Moralidade", a relação sujeito/objeto tematiza-se pela relação entre vontade particular subjetiva e seu objeto o direito e a lei moral - de modo que a vontade particular tem o universal como objeto do seu querer. Por isso que a Filosofia do Direito, enquanto sistema de realização da liberdade objetiva, estabelece uma hierarquia de objetos a partir dos quais, o eu, a vontade ou a razão em si mesma, se expressa de diferentes formas.

Já no "Direito Abstrato" o eu/vontade se determina na coisa exterior enquanto 
essa é sua propriedade. Porém, essa forma de realização exterior da vontade pressupõe, como antecedente lógico, que todos são iguais enquanto "pessoa do direto" e que, portanto, devem ser respeitados como tais. Desse modo, a vontade ao se determinar na coisa exterior pressupõe implicitamente o reconhecimento de todos os demais, de que aquela coisa representa a efetividade da minha vontade particular, mas implica reciprocamente que eu reconheça o mesmo direito para o outro. $\mathrm{O}$ desrespeito a esse princípio, que significa o não reconhecimento do outro como "pessoa do direito", terá sua resolução prática, somente na "Eticidade", através da administração da justiça.

Hegel então avalia que, na "Moralidade", o eu se encontra consigo mesmo na interioridade da vontade na forma de um propósito que visa uma ação prática na qual ele se determina enquanto saber e quer da vontade particular. Ora, como a vontade só se determina objetivamente pela mediação da ação, podem conectar-se à aquela ação específica, consequências não previstas ou não desejadas pelo agente, mas que decorrem dela necessariamente ou aleatoriamente devido ao elemento universal presente em toda a ação particular. O dever da vontade é saber desse universal presente na ação particular. Nisso consiste a sua intenção. Ela é, afinal, a universalização daquilo que subjetivamente estava presente no propósito. Isso, no entanto, requer do agente a consciência de que a vontade ao se exteriorizar pela ação, conecta-se à uma multiplicidade de consequências que podiam ou deviam ser sabidas pelo agente. É daqui que emerge a responsabilidade da vontade. A moralidade é, portanto, o domínio no qual o eu é considerado como sujeito volitivo onde a oposição entre vontade particular e vontade universal foram internalizadas e superadas. Em outras palavras, isso significa dizer que a vontade particular está em conformidade com a vontade universal não por mera adequação do eu a uma imposição externa, mas por um ato de volição do próprio eu. Por isso que o foco central da moralidade é a responsabilidade moral do sujeito pelos seus atos e suas realizações efetivas. A moral não se limita a seguir meros princípios formais e abstratos ou meras intenções ou disposições interiores. Como bem nos adverte Wood, 2014, p. 255): “a teoria recomenda princípios quando estes podem ser seguidos por um 'eu' e recomenda fins quando estes podem ser procurados". Nisso consiste o direito de o sujeito encontrar satisfação nas suas escolhas e nas suas ações (cf. FD \& 121). Do agente moral se requer que faça o que é justo e que dê as razões de porque isso é justo. É isso que dá valor e dignidade à ação moral. Se, por um lado, Hegel se aproxima de Kant ao afirmar que o dever seja cumprido pelo dever, por outro lado, ele se afasta dele num aspecto particular: que o dever deva ser praticado, unicamente, por amor ao dever (cf. FD \& 133). A partir dessa critica a Kant, Hegel quer deixar claro que é preciso extrair o verdadeiro conteúdo de nossos deveres a partir da vida ética, ou seja, das relações sociais e institucionais, nas quais o sujeito está inserido, uma vez que é nesse contexto que a ação da moral está circunscrita.

Já, para Hegel, a consciência do sujeito moral é o elemento fundamental e indispensável porque representa o verdadeiro reconhecimento do valor da vontade subjetiva que é a característica específica do mundo moderno. Porém, esse não é o único critério a ser levado em conta. Hegel reconhece que a consciência moral moderna pode incorrer em ambiguidades na medida em que o egocentrismo do agente moral, pode cair em contradições ao eleger sua convicção subjetiva como critério para a ação moral. Ele pode, ao partir de sua convicção, tomar o mal como sendo o bem e, com isso, converter o bem num mal. Aos olhos de Hegel, a ética da convicção é absolutamente falha ao pretender fundamentar a ação moral única e exclusivamente na consciência. Esse apelo à consciência, no mundo moderno, tem o seu valor, mas esse 
não pode ser reduzido à subjetividade do agente moral. Como sair desse impasse? $\mathrm{O}$ apelo à autoconsciência é fundamental, mas não pode colocar-se como critério único para qualificar a ação como moralmente correta, porque, desse modo, cair-se-ia num extremo subjetivismo: a denominada ética da convicção. Fato é que essa posição ética abole as fronteiras entre o bem e o mal, porque qualquer conteúdo com base na convicção poderia converter-se, imediatamente, tanto no bem como no mal, dado que o critério que os qualifica como tais é a sua própria convicção, ou seja a pura subjetividade. Hegel pretende superar a ética da convicção a partir do conceito de "Eticidade".

\section{Conclusão}

Para concluir, pode-se afirmar que a concepção de Hegel, o âmbito da "Moralidade", ao se confrontar em última instância com o mal, exige que ela seja transcendida pela "Eticidade", porque enquanto vida ética objetiva, esta, insere o sujeito moral no contexto das relações sociais e institucionais objetivas. Ora, pois, é por meio delas, que a vontade subjetiva encontra sua satisfação. Por isso, o ponto de vista ético é o momento da reflexão crítica sobre as próprias instituições sociais, na medida que elas representam a mediação objetiva da vontade humana.

Isso explica porque, para Hegel, a esfera da Moralidade tem que ser suprassumida pela "Eticidade" porque é nela que razão e sensação se confrontam com situações concretas, onde, a vontade particular extrai seu juízo prático a partir das regras gerais, juridicamente reconhecidas, e subjetivamente aceitas, como as formas concretas de realização da vontade subjetiva no contexto das relações sociais objetivas.

\section{REFERÊNCIAS}

AMENGUAL COLL, Gabriel et ali. Estudios sobre la "Filosofia del Derecho"de Hegel. Madrid: Centro de Estudios Constitucionales, 1989.

. La moral como derecho: estudios sobre la moralidad en la Filosofía del Derecho de Hegel. Madrid: Editorial Trotta. 2001.

ALLEN W. WOOD, “A ética de Hegel”, Cap. 7, pág. 255. In. FREDERICK C. BEISER (ORG.). [Guilherme Rodrigues Neto]. São Paulo: Ideias \& Letras, 2014. Companions \& Companions)

BEISER, Frederick C. (Org.) et ali. Hegel. Tradução de Guilherme Rodrigues Neto. São Paulo: Ideias \& Letras, 2014. Companions \& Companions)

HEGEL, G. W. F. Grundlinien der Philosophie des Rechts oder Naturrecht und Staatswissenschaft im Grundrisse. Frankfurt am Main: Suhrkamp, 1986 (Taschenbuch Wissenschaft).

- Princípios de la filosofía del derecho: o derecho natural y ciencia política. Buenos Aires: Editorial Sudamericana, 1975.

. Linhas fundamentais da filosofia do direito, ou, Direito natural e ciência do estado em compêndio. Tradução de Paulo Meneses...[et al.]. São Leopoldo, RS: Ed. UNISINOS, 2010.

- Enciclopédia das Ciências Filosóficas em Compêndio (1830). Tradução de Paulo Meneses. São Paulo: Loyola, 1995. (vol.III)

RITTER, Joachim. "Moralidad y eticidad. Sobre la confrontación de Hegel con la ética kantiana". In: Amengual Coll, Gabriel et ali. Estudios sobre la "Filosofía del Derecho"de Hegel. Madrid: Centro de Estudios Constitucionales, 1989. 


\section{Notas}

1 Sobre a gênese do conceito de pessoa em Hegel (cf. COLL, 2001, nota 04, p. 61). A pessoa, no começo da FD, enquanto vontade geral, é apenas em si, não ainda para si ou efetiva. Pela superação (Aufhebung) do delito, a vontade geral (em si) passa a ser para si na moralidade. A pessoa se converte, aqui, em sujeito moral (cf. FD § 105). Isso demonstra que a pessoa, no Direito Abstrato, tem um caráter limitado e uma significação específica. "O conceito de pessoa em Hegel é puramente jurídico, relativo ao âmbito da exterioridade, e reduzido, assim, ao âmbito jurídico privado. Hegel reduz o conceito de pessoa neste âmbito do Direito Abstrato, que é privado, constituído por relações interpessoais e, portanto, no qual somente aparece a vontade comum, todavia não a vontade geral propriamente dita" (COLL,2001, p. 62). [Tradução nossa] 